(2) Open Access Full Text Article

CASE REPORT

\title{
Posterior reversible encephalopathy syndrome
} following an inadvertent dural puncture during an emergency laparotomy for ischemic colitis a case report

\author{
This article was published in the following Dove Press journal: \\ Local and Regional Anesthesia \\ 20 January 2014 \\ Number of times this article has been viewed
}

\author{
Reena Shah \\ Agnieszka Kubisz-Pudelko \\ Jeremy Reid \\ Yeovil District Hospital, Yeovil, UK
}

\begin{abstract}
Posterior reversible encephalopathy syndrome (PRES) is a clinico-neuroradiological syndrome characterized by various symptoms of neurological disease. It has commonly been reported in association with acute hypertension, pre-eclampsia, eclampsia, sepsis, and exposure to immunosuppressants. Here, we report on a normotensive woman who developed a severe frontal headache, visual disturbances, and hypertension 3 days after undergoing an emergency laparotomy for ischemic colitis during which she suffered an inadvertent dural puncture. Neuro-imaging revealed features consistent with PRES. The patient went on to make a good recovery, being discharged 21 days postoperatively, with only minor visual disturbances and memory problems. This case highlights the importance of awareness of PRES to all specialties. On reviewing the literature, we feel that PRES may be a potential differential diagnosis to post-procedural neurological symptoms in those patients undergoing routine procedures such as spinal anesthetics or lumbar punctures.
\end{abstract}

Keywords: PRES, neurological disease, lumbar puncture, spinal anesthetic

\section{Introduction}

Posterior reversible encephalopathy syndrome (PRES) has been well reported over the years since it was first described by Hinchey et al in $1996 .{ }^{1}$ The typical clinical signs consist of various associations of seizure activity, consciousness impairment, headaches, visual abnormalities, and focal neurological signs, as well as radiologic findings of focal vasogenic edema involving both the grey and white matter. The underlying pathophysiology of PRES remains poorly understood. However, the syndrome is most commonly reported in association with acute hypertension, pre-eclampsia, eclampsia, renal disease, sepsis, and exposure to immunosuppressants. ${ }^{2-5}$ Here, we report a case of PRES in a 62-year-old well controlled hypertensive lady who suffered an inadvertent dural puncture while undergoing an emergency laparotomy for ischemic colitis. To the best of our knowledge, this is the first case study of PRES in a surgical patient with an accidental dural puncture.

\section{Case presentation}

A 62-year-old woman presented acutely with severe sudden onset left-sided abdominal pain and several episodes of diarrhea with blood mixed in with stool. Her past medical history included coeliac disease and hypertension that was well controlled with ramipril $10 \mathrm{mg}$ daily. On admission, observations were: temperature $36.4^{\circ} \mathrm{C}$, blood pressure
Yeovil District Hospital

Higher Kingston, Yeovil,

Somerset BA2I 4AT, UK

Tel +44 I935475 I22

Email reena.shah@doctors.org.uk submit your manuscript | www.dovepress.com

Dovepress

http://dx.doi.org/1 0.2147/LRA.S57660
Local and Regional Anesthesia 20|4:7 I-4

(c) (i) (5) 2014 Shah et al. This work is published by Dove Medical Press Limited, and licensed under Creative Commons Attribution - Non Commercial (unported, v3.0) License. The full terms of the License are available at http://creativecommons.org/licenses/by-nc/3.0/. Non-commercial uses of the work are permitted without any further permission how to request permission may be found at: http://www.dovepress.com/permissions.php 
$115 / 50 \mathrm{mmHg}$, heart rate $75 \mathrm{bpm}$, respiratory rate 16 , and oxygen saturations of $99 \%$ breathing on air. Examination revealed localized peritonitis of the left abdomen, and rectal examination showed altered blood with no stool. A computed tomography (CT) scan of her abdomen and pelvis showed an appearance consistent with colitis involving the transverse and sigmoid colon, the distribution suggesting ischemic colitis. She was initially managed conservatively with analgesia and intravenous antibiotics. Flexible sigmoidoscopy the following day showed an ischemic splenic flexure, and the decision was made for the patient to undergo a laparotomy. Preoperatively, the patient remained normotensive.

On the second day of her admission, the patient was taken to theater for a laparotomy. A low thoracic epidural was attempted for postoperative pain relief; however, the procedure was abandoned after one attempt due to a dural tap. Consequently, the patient had general anesthesia with systemic opioid analgesia and a rectus sheath block. Intraoperative findings revealed an ischemic left colon and proximal sigmoid colon; therefore, she underwent a Hartmann's procedure. Intraoperatively, the patient remained hemodynamically stable, with an average blood pressure of 120/60 $\mathrm{mmHg}$. Postoperatively, the patient was commenced on a morphine patient-controlled analgesia for pain relief and was anticoagulated for the ischemic colitis. Investigations towards underlying conditions likely to have caused the ischemic colitis were also carried out. Screening for presence of the anti-phospholipid antibody, JAK2 mutation, and thrombophilia proved negative.

Postoperatively, the patient developed an ileus. This was managed conservatively with nasogastric drainage and intravenous fluids. Her blood pressure rose from an average of $150 / 80 \mathrm{mmHg}$ on postoperative day 1 to $190 / 80 \mathrm{mmHg}$ on postoperative day 3 , despite remaining on her usual dose of ramipril. On postoperative day 3 , the patient complained of a frontal headache and "cloudy vision." The headache and rising blood pressure was initially thought to be due to postoperative pain and dural tap; on postoperative day 3 , she was commenced on a second antihypertensive, amlodipine. On postoperative day 4, headache, severe hypertension, and worsening vision continued. Neurological examination revealed no focal abnormality; however, fundoscopy showed blurred discs but no retinal hemorrhages or exudates. The patient was commenced on bisoprolol and underwent an urgent CT head scan (Figure 1).

The CT head scan revealed bilateral areas of low attenuation in the left occipital lobe and to a lesser extent in the right occipital lobe. There were also some patchy areas of

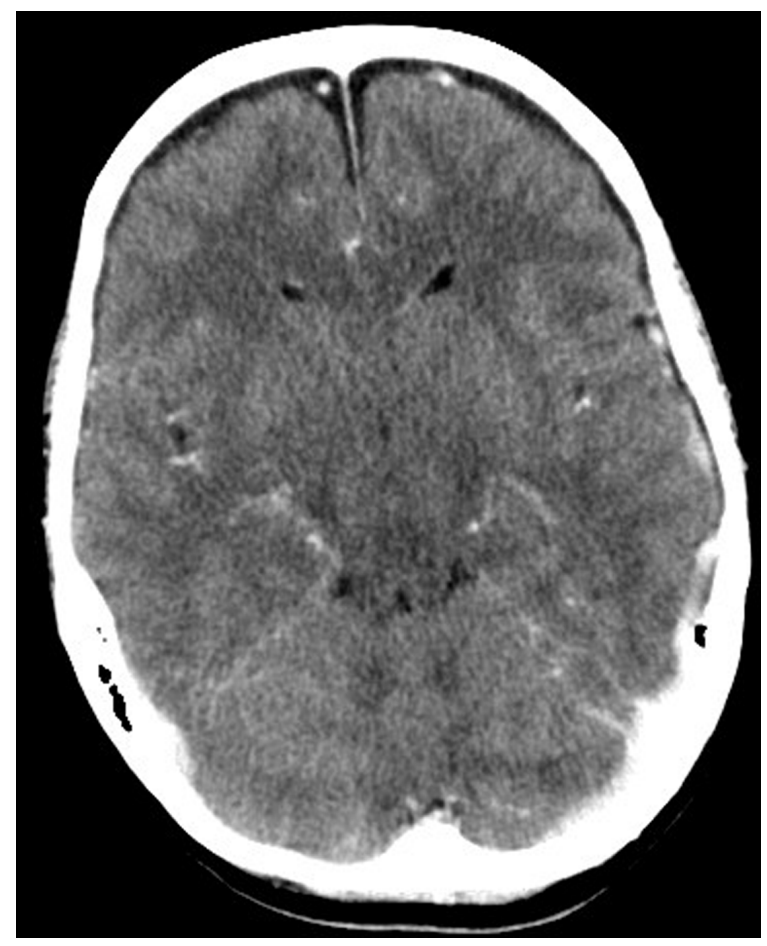

Figure I Computed tomography scan of head.

low attenuation in the right and left cerebellar hemispheres. There was neither mass effect nor enhancement.

A subsequent magnetic resonance imaging scan of the head and magnetic resonance venography (Figure 2) showed patchy white matter edema most markedly in the occipital

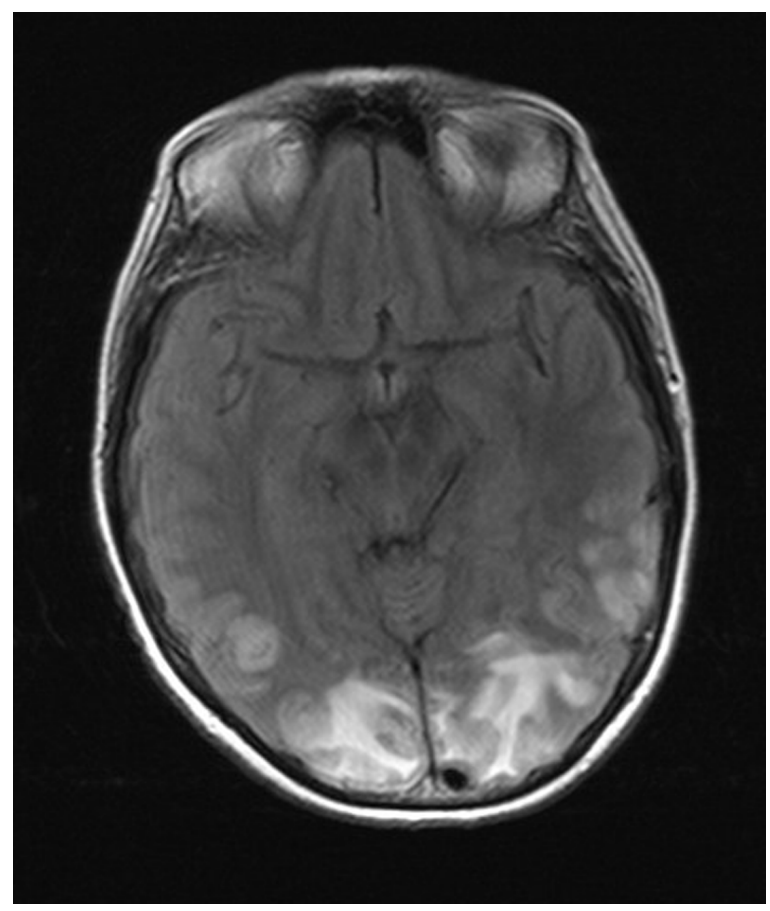

Figure 2 Magnetic resonance imaging of head. 
lobes but extending anteriorly to reach the frontal lobes, consistent with PRES.

Despite these findings, blood pressure continued to be controlled with oral medication. However, on postoperative day 6 , the patient developed status epilepticus. Repeat head CT excluded an intracerebral bleed. The patient was loaded with intravenous phenytoin, intubated, and blood pressure was tightly controlled with a mean arterial pressure of $85 \mathrm{mmHg}$. The patient was extubated the following day. Blood pressure continued to be tightly controlled with regular antihypertensives, and she remained on phenytoin to prevent further seizures.

The patient continued to improve and was discharged 21 days postoperatively with blood pressure controlled (systolic readings of 120-130 $\mathrm{mmHg}$ ) on her usual dose of ramipril plus $10 \mathrm{mg}$ amlodipine daily. The only residual neurological defects that she experienced on discharge were minor visual disturbances and memory problems.

\section{Discussion}

PRES is a clinico-neuroradiological entity initially described by Hinchey et al in $1996 .^{1}$ The typical clinical signs consist of headache, visual disturbances, seizures, and altered mental state, which are associated with distinctive neuroimaging findings of posterior cerebral white matter edema. Most reported cases have been recognized to be in association with acute hypertension, immunosuppressive therapies, sepsis, renal failure, pregnancy, and systemic lupus erythematous. ${ }^{2-5}$

The pathophysiology of PRES continues to be debated; however, regardless of the mechanism of initiation, it involves the development of edema in affected areas of the brain. ${ }^{6}$ Two contradicting main theories, resulting in vasogenic cerebral edema as a result of disruption to the blood-brain barrier from cerebral blood perfusion disturbances, have been proposed. One involves impaired cerebral autoregulation leading to an increase in cerebral blood flow, and the other involves endothelial dysfunction with cerebral hypoperfusion from vasoconstriction. ${ }^{7}$

PRES is usually reversible; however, it can lead to irreversible neurological damage or even death as a result of progressive cerebral edema, or intracerebral hemorrhage. ${ }^{6,8}$ Treatment for PRES by symptom control and resolution of the underlying implicating factor is critical as soon as the condition is recognized, to avoid the risk of permanent neurological insult. ${ }^{9}$

Our patient had onset of a frontal headache without postural features 3 days postoperatively following an emergency laparotomy with an inadvertent dural tap during anesthesia and a postoperative ileus. She was noted to be hypertensive, with a mean arterial pressure of $>120 \mathrm{mmHg}$ at the same time. These symptoms were thought to be due to a post-dural tap headache, malabsorption of antihypertensive medication due to a postoperative ileus and uncontrolled pain. Alfery et $\mathrm{al}^{10}$ stated that the diagnosis of a post-dural headache should not be formed unless a headache with postural features is present. In this scenario, other intracranial causes of headache should be sought. A diagnosis of PRES was not suspected and was only established in this case following neuroimaging.

We acknowledge that there is a degree of overlap between the diagnosis of PRES and hypertensive encephalopathy, and perhaps blood pressure should have been controlled more aggressively with intravenous blood pressure agents from the start due to malabsorption of oral medications due to a postoperative ileus. However, did uncontrolled hypertension lead to PRES? Or, did PRES lead to hypertension? Our patient started to complain of headaches prior to changes in her blood pressure, and fundus examination did not reveal retinal hemorrhages and exudates, which are characteristic of hypertensive encephalopathy, ${ }^{11}$ therefore swaying to a diagnosis of PRES leading to uncontrolled hypertension.

The occurrence of PRES following epidural or spinal anesthetic has been described before in patients with uncontrolled preoperative hypertension, parturient patients, or those who have received chemotherapy. ${ }^{12-16}$ Could PRES have been attributed to the dural puncture, and should it be considered as a differential diagnosis of post-dural puncture headache? In 1956, prior to when PRES was first described, Vandam and Dripps ${ }^{17}$ reported symptoms of visual disturbances such as diplopia or cortical blindness after dural puncture.

A possible theory leading to the development of PRES following a post-dural puncture headache is through the Monro-Kellie hypothesis, leading to cerebral hyperperfusion and disruption of the autoregulatory effect of the blood-brain barrier, culminating in cerebral vasogenic edema. ${ }^{18}$ Following a dural puncture, the rate of cerebrospinal fluid (CSF) loss is greater than that of CSF production. The loss of CSF results in intracranial hypotension leading to vasodilation of cerebral blood vessels as a compensatory mechanism (Monro-Kellie hypothesis) to increase cerebral blood volume. Magnetic resonance imaging scans performed in the presence of a post-dural puncture headache frequently reveal "sagging" of the intracranial structures and may demonstrate meningeal enhancement. ${ }^{19}$ The meningeal enhancement is thought to be characteristic of vasodilation of thin-walled vessels in response to the intracranial hypotension. ${ }^{19}$ The white matter 
edema in patients with PRES is usually localized in posterior areas. This might be explained by heterogeneity of the autonomic innervation of the intracranial arterioles, with less nerve representation around the vessels in the posterior cerebral circulation, which are therefore more vulnerable to the effects of hyperperfusion. ${ }^{20}$

Here we describe the management of a well-controlled hypertensive patient who developed PRES following an inadvertent dural puncture during an emergency laparotomy for ischemic colitis. We are unable to give the exact pathogenesis of PRES in this case, but feel that preexisting hypertension and an inadvertent dural tap are the main contributing factors resulting in cerebral vasogenic edema. We believe that the awareness of PRES is essential to all specialties, especially anesthesiology, surgery, and obstetrics, due the nonspecific clinical scenario developed in patients with PRES. It is important to be familiar with this syndrome as well as the possible causative factors, including dural taps, in order to establish early diagnosis and treatment of this condition and reduce adverse outcomes.

\section{Disclosure}

The authors report no conflicts of interest in this work.

\section{References}

1. Hinchey J, Chaves C, Appignani B, et al. A reversible posterior leukoencephalopathy syndrome. $N$ Engl J Med. 1996;334:494-500.

2. Hauser RA, Lacey DM, Knight MR. Hypertensive encephalopathy: magnetic resonance imaging demonstration of reversible cortical and white matter lesions. Arch Neurol. 1988;45(10):1078-1083.

3. Schwaighofer BW, Hesselink JR, Healy ME. MR demonstration of reversible brain abnormalities in eclampsia. J Comput Assist Tomogr. 1989;13(2):310-312.

4. Bartynski WS, Boardman JF, Zeigler ZR, et al. Posterior reversible encephalopathy syndrome in infection, sepsis, and shock. AJNR Am J Neuroradiol. 2006;27(10):2179-2190.
5. Appignani BA, Bhadelia RA, Blacklow SC, et al. Neuroimaging findings in patients on immunosuppressive therapy: experience with tacrolimus toxicity. AJR Am J Roentgenol. 1996;166(3):683-688.

6. Legriel S, Pico F, Azoulay E. Understanding posterior reversible encephalopathy syndrome. Annu Update Intensive Care Emerg Med. 2011;1:631-653.

7. Bartynski WS. Posterior reversible encephalopathy syndrome, part 2: controversies surrounding pathophysiology of vasogenic oedema. AJNR Am J Neuroradiol. 2008;29:1043-1049.

8. Neill TA, Hemphill JC. Reversible posterior leukoencephalopathy syndrome. 2013. Available from: http://www.uptodate.com/contents/ reversible-posterior-leukoencephalopathy-syndrome\#H1. Accessed December 11, 2013.

9. Mak A, Chan BP, Yeh IB, et al. Neuropsychiatric lupus and reversible posterior leucoencephalopathy syndrome: a challenging clinical dilemma. Rheumatology (Oxford). 2008;47:256-262.

10. Alfery D, Marsh M, Shapiro H. Post-spinal headache or intracranial tumour after obstetric anesthesia. Anesthesiology. 1979;51:92-94.

11. Susanto I. Hypertensive encephalopathy. 2013. Available from: http://emedicine.medscape.com/article/166129-overview. Accessed December 11, 2013.

12. Rangi PS, Partridge WJ, Newlands ES, Waldman AD. Posterior reversible encephalopathy syndrome: a possible late interaction between cytotoxic agents and general anaesthesia. Neuroradiology. 2005;47:586-590.

13. Ho CM, Chan KH. Posterior reversible encephalopathy syndrome with vasospasm in a postpartum woman after postdural puncture headache following spinal anaesthesia. Anesth Analg. 2007;105:770-772.

14. Eran A, Barak M. Posterior reversible encephalopathy syndrome after combined general and spinal anaesthesia with intrathecal morphine. Anesth Analg. 2009;108(2):609-612.

15. Minai F, Hasan S, Sheerani M. Post-dural puncture posterior reversible encephalopathy syndrome. J Coll Physicians Surg Pak. 2011;21:37-39.

16. Yi J, Ha S, Kim Y, Choi E. Posterior reversible encephalopathy syndrome in an untreated hypertensive patient after spinal surgery under general anaesthesia. Korean J Anesthesiol. 2011;60(5):369-372.

17. Vandam L, Dripps R. Long-term follow up of patients who received 10098 spinal anaesthetics. JAMA. 1956;161:586-591.

18. Grant R, Cordon B, Hart I, Teasdale G. Changes in intracranial CSF volume after lumbar puncture and their relationship to post-LP headache. J Neurol Neurosurg Psychiatry. 1991;54:440-442.

19. Hannerz J, Ericson K, Bro Skejo H. MR imaging with gadolinium in patients with and without post-lumbar puncture headache. Acta Radiol. 1999;40:135-141.

20. Beausang-Linder M, Bill A. Cerebral circulation in acute arterial hypertension - protective effects of sympathetic nervous activity. Acta Physiol Scand. 1981;111:193-199.
Local and Regional Anesthesia

\section{Publish your work in this journal}

Local and Regional Anesthesia is an international, peer-reviewed, open access journal publishing on the development, pharmacology, delivery and targeting and clinical use of local and regional anesthetics and analgesics. The journal welcomes submitted papers covering original research, basic science, clinical studies, reviews \& evaluations,

\section{Dovepress}

guidelines, expert opinion and commentary, case reports and extended reports. The manuscript management system is completely online and includes a very quick and fair peer-review system, which is all easy to use. Visit http://www.dovepress.com/testimonials.php to read real quotes from published authors. 